\title{
T.А. Кискидосова
}

\section{БРАЧНОСТЬ, РОЖДАЕМОСТЬ И СМЕРТНОСТЬ ПРАВОСЛАВНОГО НАСЕЛЕНИЯ СИБИРСКОГО ГОРОДА ВО ВТОРОЙ ПОЛОВИНЕ ХІХ В. (НА ПРИМЕРЕ МЕТРИЧЕСКИХ КНИГ ПРАВОСЛАВНЫХ ЦЕРКВЕЙ МИНУСИНСКА)}

\begin{abstract}
На основе метрических книг двух православных церквей рассматриваются демографические процессы в Минусинске во второй половине XIX в. Исследованы сезонность рождений, венчаний и смертей, половозрастные показатели смертности, общая демографическая динамика. Отмечено, что для горожан была характерна традиционная модель демографического поведения. На протяжении изучаемого периода сохранялись колебания рождаемости и смертности. Увеличение смертности наблюдалось в большей степени в зимние и летние месяцы.

Ключевые слова: историческая демография; город; Минусинск; православные; брачность; рождаемость; смертность.
\end{abstract}

В современной сибирской историографии города являются объектом специального демографического изучения. В трудах А.Р. Ивонина, В.А. Скубневского, Ю.М. Гончарова, Д.Е. Сарафанова, М.В. Винник, В.Н. Владимирова, В.В. Плодуновой, И.Г. Силиной и других рассмотрены демографические процессы, происходившие в сибирских городах в дореволюционный период [1-7]. Историко-демографические исследования развиваются на основе комплексного использования разных видов источников. Авторы используют как первичные материалы, так и агрегированную информацию.

Среди источников исторической демографии особое место занимают материалы массового церковного учета населения, включающие в себя набор документов, где ведущую роль играют метрические книги, клировые ведомости и исповедные росписи (ведомости), формировавшиеся в рамках церковной документации. Введение в научный оборот церковных источников позволяет рассмотреть различные аспекты народонаселения определенного региона. В метрических книгах содержится детальный анализ демографической информации, начиная с акта рождения, бракосочетания и смерти.

Документы о народонаселении церковного происхождения, с одной стороны, являются ценным источником в изучении демографических процессов, с другой стороны, существует ряд проблем, связанный с достоверностью и точностью данных документов. В работе с метрическими книгами существуют такие недостатки, как нерегулярность и неточность данных, отсутствие некоторых сведений, небрежность и невнимательность в заполнении граф, а также плохая сохранность источника. Исследователи отмечали, что агрегированные данные церковного учета дают возможность приблизительно оценить основные демографические показатели режима воспроизводства населения: брачность, общую и специальную рождаемость, общую и возрастную смертность, возрастную структуру и т.д. Как справедливо заметил Б.Н. Миронов, неточность церковного учета обязательно следует принимать в расчет, но это не должно останавливать исследователей, так как совершенно точных данных вообще нет [8. С. 46].

Во второй половине XIX в. из всех городов Енисейской губернии Минусинск являлся одним из мо- нонациональных городов с преобладающей долей русского населения. Среди всех конфессиональных групп доминировала группа православных. В 1863 г. православные составляли 94,9\% от всего населения Минусинска. К 1890 г. удельный вес этой конфессиональной группы снизился до 86,3\% [9. С. 40]. Метрические книги Минусинска велись по тому же принципу, что и в других российских городах. Структура ведения метрических книг была общей для всех. Как правило, они состояли из трех основных частей: «О рождении», «О бракосочетании» и «Об умерших». Создание базы данных позволит изучить соотношение возраста женихов и невест, сезонное распределение браков и крещений, возрастные особенности смертности и ряд других вопросов. В конце сведений каждой церкви подводились итоги, т.е. составлялись специальные таблицы, в которых подсчитывалось общее количество рожденных детей мужского и женского пола в течение года, при этом учитывалось число законнорожденных и незаконнорожденных. Таблицы учитывали количество браков и супружеских пар, а также общее количество умерших мужчин и женщин. Отдельно была представлена таблица, в которой расписывались по возрастным группам и полу умершие, фиксировались причины смерти. Составленные таблицы являлись своеобразным подведением итогов.

Для проведения историко-демографического анализа источником стали хранящиеся в Минусинском городском архиве (МУ МГА) метрические книги прихожан Спасского собора за 1857-1898 гг. (Ф. 12) и Троицкой церкви - за 1875-1898 гг. (Ф. 59). Спасский собор и Троицкая церковь находились в ведении Енисейской духовной консистории. Метрические книги двух церквей были лишь частично использованы в научных работах исследователей. В основном они вызывают интерес у краеведов и отдельных лиц, которые составляют родословные.

Обработка метрик начинается с так называемого агрегативного анализа, который включает распределение крещений (рождений), похорон (смертных случаев) и венчаний (заключенных браков) по месяцам, по годам, а в сельской местности - по времени сбора урожая (июль - август). На основе данных о численности населения прихода вычисляются рождаемость, смертность и брачность населения. Таким образом, первоначальную характеристику демографических 
показателей прихода можно получить при агрегативной обработке первичных материалов [10. С. 88].

Интерес представляет вопрос о сезонности браков в сибирских городах. В табл. 1 приведены сведения о распределении браков по месяцам среди православных жителей Минусинска в 1874-1898 гг. (на основе метрических книг Спасского собора и Троицкой церкви). В разные годы $(1874,1889,1890$ и 1898) распределение браков по месяцам в относительном отношении было приблизительно одинаковым. Например, наибольшее количество браков православных минусинцев приходилось на зимний (январьфевраль), весенний (апрель-май), летний (июль) и осенний (ноябрь) периоды. Основная масса венчаний была в январе, в этом месяце доля браков составила: в 1874 г. $-37,1 \%$, в 1889 г. $-34,7 \%$, в 1890 г. $-40,8 \%$ в 1898 г. - 29,4\%. Наименьший удельный вес заключенных браков приходился на летний период: июнь (1874 г. - 2,9\%, 1889 г. - 2,8\%, 1890 г. - 0, 1898 г. $1,2 \%)$ и август $(1874$ г. - 0, 1889 г. - 2,8\%, 1890 г. $1,3 \%, 1898$ г. - 2,4\%). Браки не заключались в марте и декабре (исключение в 1890 г. - 3 венчания в марте по данным Спасского собора).

Помесячные колебания в количестве заключенных браков были связаны с религиозными и экономическими факторами. В периоды великих постов (Великого, Рождественского, Петрова и Успенского), дней масленицы (неделя перед Великим постом), пасхальных дней, в кануны и в самые дни церковных праздников, а также накануне среды, пятницы и воскресенья в течение всего года православной церковью запрещались венчания. Аграрные циклы также играли значительную роль в сезонности браков. После сбора урожая и окончания сельскохозяйственных работ начинался период проведения свадеб в осенний период, в декабре в связи с постом и Рождеством заключение браков замирало и резко активизировалось в январе и феврале [11. С. 169]. В Восточной Сибири осенних свадеб было немного, что связано с хозяйственно-бытовыми причинами. В это время деятельность населения была связана с поставками на прииски, охотничьим промыслом в тайге, рубкой и перевозкой дров и т.Д. [7. С. 133]. В Минусинске в осеннее время удельный вес свадеб до ноября был невысок.

Исследователи заметили, что в осенний период вновь начинался всплеск свадеб в городах, в деревнях апогей браков наступал в зимний период. Занятия горожан отличались от хозяйственной деятельности крестьян. Сельским жителям было удобнее проводить в зимний период свадьбы по ряду хозяйственнобытовых причин, таким, например, как окончание продажи продукции крестьянского хозяйства, возвращение с тайги с охотных промыслов мужского населения, приход в семью работницы к новому сезону [2. С. 73]. Нельзя не отметить и тот факт, что согласно народным традициям лучшее время для зачатия ребенка приходится на зимний период (январьфевраль). Дети, рожденные в осеннее время, были физически наиболее развиты. В то же время дети, зачатые в период осенних свадеб и рожденные весной и летом, были наиболее слабыми. В соответствии с церковным календарем наиболее многочисленные зим- ние свадьбы (и зачатия) должны были приводить к всплеску рождаемости в осенние месяцы, осенние свадьбы - к увеличению рождаемости весной - летом, что в реальности не всегда наблюдалось (но подъемы рождаемости встречались и в начале года). Церковные запреты в регулировании рождаемости соблюдались не всегда. Тем не менее сезонность зачатий / рождений во многом зависела от сезонности вступления в брак, что, в свою очередь, определялось православными канонами.

Интерес представляет вопрос о сезонности зачатий и рождений. Рассмотрим годовой цикл рождений православного населения Минусинска в 1889-1892 гг. на основе метрических книг (см. табл. 2). Исходя из представленных сведений и подсчета, можно сделать вывод о том, что на протяжении четырех лет в городе наблюдалась сезонность рождений. Наивысший пик рождений приходился на июнь (в среднем за 4 года было 9,9\%), июль $(9,2 \%)$ и декабрь $(8,9 \%)$. Следовательно, наибольшее количество рождений в июнеиюле и декабре свидетельствовало о том, что дети, рожденные в эти месяца, были зачаты в сентябреоктябре и марте. Также за четырехлетний период отмечались в среднем высокие показатели рождений в сентябре $(8,4 \%)$, зачатие происходило в декабре, т.е. во время постных дней. Исследователи заметили, что строгий пост и половое воздержание соблюдались деревенскими жителями. Горожане менее строго воздерживались от половой жизни во время поста [2. С. 81]. Наименьшая доля рождений у православных минусинцев приходилась на январь (в среднем за 4 года - 6,0\%), рожденные в этом месяце были зачаты в апреле.

В табл. 3 приведены сведения и подсчет о возрастно-половой смертности в Минусинске в 1875 и 1898 гг. Показатели смертности, как и рождаемости, зависели от возрастно-половой структуры населения. Основная доля смертности приходилась на младенческий возраст (от рождения до года) или на возрастную группу «менее года». По данным Спасского собора, в 1857 г. в Минусинске число всех умерших достигло 161 чел., в том числе 96 чел. относились к возрастной группе до 1 года.

Таким образом, доля умерших младенцев составила 59,6\%. В последующие годы младенческая смертность продолжала оставаться высокой. В 1875 г. удельный вес умерших младенцев составил 50,9\%, в 1890 г. - 42,9\%, в 1898 г. - 44,6\%. Подобные показатели летальности младенцев были характерны для многих российских городов того времени. В стране господствовал традиционный тип смертности [12. С. 133-134]. Большая младенческая смертность являлась результатом острой нехватки медицинских работников. В рассматриваемый период Минусинск не отличался от других сибирских городов. Например, в Барнауле в 1870 г. доля умерших младенцев составила $47,5 \%$, в 1882 г. $-49,4 \%$ [13].

Причинами высокой смертности возрастной группы «от 0 до 1 года» были неумелый уход за детьми, неправильное кормление, антигигиенические обряды, непосильный труд во время беременности, плохое питание и недостаток медицинской помощи. Повы- 
шенные показатели детской смертности связаны еще и с низким культурным уровнем матерей. Особенно много умирало младенцев в первые месяцы жизни, когда слабый организм на первом году жизни сталкивался с неблагоприятными условиями жизни, не выдерживал и погибал. Младенцы и дети погибали от таких болезней, как «родимец», «понос», рвота, корь, коклюш, оспа и золотуха. Среди частых причин смерти грудничков указывалось «слаборождение» младенцев [14. Ф. 797. ОП. 72. Д. 391. Л. 133]. Священнослужители, не имея медицинского образования, записывали в метрических книгах народные названия заболеваний.

В возрастной группе «от 0 до 1 года» смертность мальчиков превышала смертность девочек. В 1875 г. в данной возрастной группе удельный вес умерших мальчиков составил $58,1 \%$, тогда как девочек - $41,9 \%$; в 1898 г. - 54,6\% и 45,4\% соответственно. Во всех других возрастных группах число умерших мужчин превышало число умерших женщин.

Сезонное распределение смертности минусинских прихожан во второй половине XIX в. отражено в табл. 4. В результате подсчета было выявлено, что показатели летальности чаще всего наблюдались в зимние и летние месяцы, иногда осенью. Пики смертности прихожан приходились преимущественно на декабрь-февраль, июнь-август (табл. 4). Распределение смертей по временам года во многом зависело от показателей детской смертности. Большинство детей умирало в младенческом возрасте от «родимца». В 1898 г. (по данным Спасского собора) в январе 10 из 34 смертей происходили из-за родимца, в феврале -9 из 32, в декабре - 14 из 23 [15. Ф. 12. Оп. 2. Д. 16. Л. 288 об.]. Череда разных острых инфекционных заболеваний часто способствовала летальному исходу среди детей. В 1880 г. в Минусинске в зимнее время началась эпидемия дифтерита, ставшая причиной высокой детской смертности. Вслед за дифтеритом весной последовала дизентерия. От этого заболевания скончалось несколько десятков детей [16. 24 мая]. В 1881 г. весной, а затем осенью вновь вспыхнула эпидемия дифтерита. В этом году ежедневно хоронили по 5-6 детей и подростков, умерших от данного заболевания. Волна детских смертей была остановлена только в начале 1882 г. [17. 3 января]. Минусинцы заметили, что «ни одна осень, ни одна весна не проходят без громадных жертв- смертности» [16. 24 мая].

В летнее время причинами смерти становились инфекционные желудочно-кишечные заболевания. В 1898 г., по данным Спасского собора, в июле из 38 умерших 20 чел. умерло от «поноса», в августе из $28-$ 13 соответственно. Причинами смерти могли быть сезонные простудные и инфекционные заболевания (скарлатина, корь, дизентерия и др.) [15. Ф. 12. Оп. 2. Д. 16. Л. 288 об.].

Некачественная питьевая вода провоцировала желудочно-кишечные заболевания. Свалки мусора могли располагаться недалеко от водоемов, а порой горожане загрязняли реки, протекавшие в черте города. В 1893 г. енисейский губернатор Л.К. Теляковский посетил Минусинск и обратил внимание на антиса- нитарное состояние базарной площади. Смесь навоза, нечистот и снега стекала по канавам с площади в Енисей. Река сильно загрязнялась нечистотами, а минусинцы пользовались в быту такой водой [18. 18 апреля].

На протяжении всего рассматриваемого периода в Минусинске была постоянная нехватка медицинского персонала. Городская больница, содержавшаяся за счет приказа общественного призрения, была тесна и неудобна. В 1880 г. больница располагала 35 кроватями. Предполагалось сделать пристройку к больничному зданию, что позволило бы вместить еще 10 кроватей [14. Ф. 1284. Оп. 70. Д. 309. Л. 22]. Некоторые подвижки в местном здравоохранении стали происходить к концу XIX в., когда во многих сибирских городах были мероприятия по улучшению санитарного состояния. В 1895 г. в Минусинске открылась амбулатория для бедных горожан. Инициатором создания подобной амбулатории стал прибывший из Красноярска врач И.Е. Козлов. Он был назначен заведующим лечебницей, его помощницей стала фельдшер К.Ф. Девятова. Лечебницу разместили в здании, где ранее находилась мещанская управа. Появление подобного медицинского заведения способствовало существенному снижению знахарства в городе [19. 14 апреля]. В среднем врач ежедневно принимал по 20-30 больных [19. 10 июля]. Однако проблемы нехватки врачей и оказания квалифицированной медицинской помощи оставались актуальными повсеместно.

На основе метрических книг были проанализированы показатели рождаемости и смертности православного населения Минусинска в определенные годы (табл. 5). В среднем в отдельные годы $(1857,1875$, $1889,1898)$ на 100 мальчиков рождалось 99,3 девочек. В отдельные годы женская рождаемость была выше мужской. На 100 рожденных мальчиков в 1875 г. родилось 102 девочки, в 1889 г. - 101. Мужская смертность значительно превышала женскую (на 100 умерших мужчин - 75,4 умерших женщин). Согласно подсчетам (табл. 5), соотношению рожденных по полу в Минусинске, в определенные годы второй половины XIX в. девочек рождалось меньше, чем мальчиков.

Результаты табл. 5 показали, что в рассматриваемый период наблюдался положительный демографический баланс мужчин. Средний показатель составил 78,5 умерших мужчин на 100 родившихся мальчиков. Однако смертность православного мужского населения в определенные годы превышала рождаемость. На 100 родившихся мальчиков в 1875 г. было 114,4 умерших мужчин, в 1889 г. - 100,5. Среди женщин также наблюдался положительный демографический баланс. Средняя цифра составила 76,5 на 100 новорожденных девочек. В целом рождаемость несколько превышала смертность (на 100 родившихся приходилось 88,9 умерших).

Изучение соотношения умерших по полу показало, что на протяжении второй половины XIX в. смертность среди женщин в отдельные годы $(1857,1875,1889$ и 1898 ) была ниже, чем среди мужчин. Среднее арифметическое за 1857-1898 гг. (75,3 умерших женщин на 
100 умерших мужчин) свидетельствует о большей смертности мужского населения, чем женского. Однако эти данные относительны, в некоторые годы смертность женщин значительно превышала смертность мужчин. Например, в 1890 г. на 100 умерших мужчин приходилось 140,0 умерших женщин [16. Ф. 12. Оп. 2, 12. Л. 263-278. Ф. 59. Оп. 2. Д. 160-194].

Таким образом, исходя из материалов метрических книг двух православных церквей г. Минусинска второй половины XIX в., рассмотрены демографические процессы. Для большинства горожан была свойственна единая модель демографического поведения. В городе господствовала посезонная ориентация при заключении браков. Посезонное распределение смертей показало, что пик летальности приходился на зиму и лето. На протяжении всего изучаемого времени в городе сохранялся высокий уровень смертности. Особенно высокой была детская смертность, что было обусловлено плохим состоянием медицины, антисанитарной обстановкой, частыми эпидемиями и низким культурным уровнем развития населения. На протяжении всего рассматриваемого периода наблюдались колебания рождаемости и смертности. В целом демографический баланс оставался положительным.

Распределение браков по сезонам среди православных жителей Минусинска в 1874-1898 гг.

\begin{tabular}{|c|c|c|c|c|c|c|c|c|}
\hline \multirow{2}{*}{ Месяц } & \multicolumn{2}{|c|}{1874 г. } & \multicolumn{2}{c|}{1889 г. } & \multicolumn{2}{c|}{1890 г. } & \multicolumn{2}{c|}{1898 г. } \\
\cline { 2 - 11 } & абс. & $\%$ & абс. & $\%$ & абс. & $\%$ & абс. & $\%$ \\
\hline Январь & 13 & 37,1 & 25 & 34,7 & 31 & 40,8 & 25 & 29,4 \\
\hline Февраль & - & - & 13 & 18,1 & 9 & 11,8 & 17 & 20,0 \\
\hline Март & - & - & - & - & 3 & 3,9 & - & - \\
\hline Апрель & 3 & 8,6 & 5 & 6,9 & 9 & 11,8 & 3 & 3,5 \\
\hline Май & 2 & 5,7 & 8 & 11,1 & 6 & 7,9 & 8 & 9,4 \\
\hline Июнь & 1 & 2,9 & 2 & 2,8 & - & - & 1 & 1,2 \\
\hline Июль & 2 & 5,7 & 5 & 6,9 & 5 & 6,6 & 9 & 10,6 \\
\hline Август & - & - & 2 & 2,8 & 1 & 1,3 & 2 & 2,4 \\
\hline Сентябрь & 2 & 5,7 & - & - & 4 & 5,3 & 3 & 3,5 \\
\hline Октябрь & 2 & 5,7 & 5 & 6,9 & 4 & 5,3 & 5 & 5,9 \\
\hline Ноябрь & 10 & 28,6 & 7 & 9,8 & 4 & 5,3 & 12 & 14,1 \\
\hline Декабрь & - & - & - & - & - & - & - & - \\
\hline Итого & 35 & 100 & 72 & 100 & 76 & 100 & 85 & 100 \\
\hline
\end{tabular}

Источники: МУ МГА. Ф. 12. Оп. 2. Д. 2. Л. 169-178, Д. 12. Л. 85-103, 242-258; Ф. 59. Оп. 2. Д. 3. Л. 57-60, Л. 150-158, Д. 16. Л. 267-287.

Годовой цикл рождений православного населения в Минусинске в 1889-1892 гг.

\begin{tabular}{|c|c|c|c|c|c|c|c|c|}
\hline \multirow{2}{*}{ Месяц } & \multicolumn{2}{|c|}{1889 г. } & \multicolumn{2}{c|}{1890 г. } & \multicolumn{2}{c|}{1891 г. } & \multicolumn{2}{c|}{1892 г. } \\
\hline & абс. & $\%$ & абс. & $\%$ & абс. & $\%$ & абс. & $\%$ \\
\hline Январь & 18 & 4,4 & 24 & 5,5 & 41 & 8,2 & 30 & 5,8 \\
\hline Февраль & 29 & 7,0 & 34 & 7,8 & 44 & 8,7 & 50 & 9,6 \\
\hline Март & 40 & 9,7 & 27 & 6,2 & 28 & 5,5 & 57 & 11,0 \\
\hline Апрель & 36 & 8,7 & 42 & 9,6 & 39 & 7,7 & 36 & 6,9 \\
\hline Май & 25 & 6,1 & 42 & 9,6 & 49 & 9,7 & 48 & 9,2 \\
\hline Июнь & 34 & 8,2 & 49 & 11,1 & 53 & 10,5 & 50 & 9,6 \\
\hline Июль & 46 & 11,1 & 44 & 10,0 & 28 & 5,5 & 52 & 10,0 \\
\hline Август & 35 & 8,5 & 23 & 5,3 & 42 & 8,4 & 49 & 9,4 \\
\hline Сентябрь & 38 & 9,2 & 37 & 8,4 & 50 & 9,9 & 32 & 6,2 \\
\hline Октябрь & 40 & 9,7 & 43 & 0,9 & 40 & 7,9 & 32 & 6,2 \\
\hline Ноябрь & 40 & 9,7 & 39 & 8,9 & 36 & 7,1 & 37 & 7,1 \\
\hline Декабрь & 32 & 7,7 & 34 & 7,8 & 55 & 10,9 & 47 & 9,0 \\
\hline Итого & 413 & 100 & 438 & 100 & 505 & 100 & 520 & 100 \\
\hline
\end{tabular}

Источники: МУ МГА. Ф. 12. Оп. 2. Д. 12. Л. 2 об. $-81,169-249$; Ф. 59. Оп. 2. Д. 3. Л. 99-148. 
Возрастно-половая смертность православного населения Минусинска во второй половине XIX в.

\begin{tabular}{|c|c|c|c|c|c|c|}
\hline \multirow[t]{2}{*}{ Возрастные группы (лет) } & \multicolumn{3}{|c|}{1875 г. } & \multicolumn{3}{|c|}{1898 г. } \\
\hline & Муж. & Жен. & Оба пола & Муж. & Жен. & Оба пола \\
\hline От 0 до 1 & 75 & 54 & 129 & 101 & 84 & 185 \\
\hline От 1 до 5 & 15 & 15 & 30 & 32 & 30 & 62 \\
\hline От 5 до 10 & 5 & - & 5 & 14 & 3 & 17 \\
\hline От 10 до 20 & 6 & 8 & 14 & 5 & 5 & 10 \\
\hline От 20 до 30 & 12 & 7 & 19 & 9 & 12 & 21 \\
\hline От 30 до 40 & 13 & 11 & 24 & 14 & 14 & 28 \\
\hline От 40 до 50 & 11 & 8 & 19 & 11 & 6 & 17 \\
\hline От 50 до 60 & 14 & 2 & 16 & 20 & 5 & 25 \\
\hline От 60 до 70 & 10 & 6 & 16 & 13 & 8 & 21 \\
\hline От 70 и старше & 12 & 7 & 19 & 21 & 8 & 29 \\
\hline Всего & 173 & 118 & 291 & 240 & 175 & 415 \\
\hline
\end{tabular}

Источники: МУ МГА. Ф. 12. Оп. 2. Д. 3. Л. 181, Д. 16. Л. 348; 198; Д. 12. Л. 42; Ф. 59. Оп. 2. Д. 1. Л. 50.

Сезонное распределение смертности православного населения во второй половине XIX в.

\begin{tabular}{|c|c|c|c|c|c|c|}
\hline \multirow[t]{2}{*}{ Месяц } & \multicolumn{2}{|c|}{1874 г. } & \multicolumn{2}{|c|}{1889 г. } & \multicolumn{2}{|c|}{1898 г. } \\
\hline & абс. & $\%$ & абс. & $\%$ & абс. & $\%$ \\
\hline Январь & 56 & 14,2 & 47 & 11,2 & 26 & 6,4 \\
\hline Февраль & 70 & 17,8 & 44 & 10,5 & 44 & 10,9 \\
\hline Мapт & 27 & 6,9 & 35 & 8,4 & 30 & 7,4 \\
\hline Апрель & 23 & 5,9 & 39 & 9,3 & 33 & 8,1 \\
\hline Май & 26 & 6,6 & 31 & 7,4 & 29 & 7,2 \\
\hline Июнь & 38 & 9,7 & 28 & 6,7 & 40 & 9,9 \\
\hline Июль & 33 & 8,3 & 40 & 9,5 & 39 & 9,6 \\
\hline Август & 32 & 8,1 & 44 & 10,5 & 52 & 12,8 \\
\hline Сентябрь & 31 & 7,9 & 23 & 5,5 & 31 & 7,7 \\
\hline Октябрь & 14 & 3,6 & 28 & 6,7 & 21 & 5,2 \\
\hline Ноябрь & 14 & 3,6 & 31 & 7,4 & 30 & 7,4 \\
\hline Декабрь & 29 & 7,4 & 29 & 6,9 & 30 & 7,4 \\
\hline Итого & 393 & 100 & 419 & 100 & 405 & 100 \\
\hline
\end{tabular}

Источники: МУ МГА Ф. 12. Оп. 2. Д. 2. Л. 207-302, Д. 12. Л. 107-125, Д. 16. Л. 288 об. 348; Ф. 59. Оп. 2. Д. 3. Л. 2-50, Д. 7. Л. 191-227.

Демографические процессы в Минусинске в 1857-1898 гг.

\begin{tabular}{|c|c|c|c|c|}
\hline Годы & 1857 & 1875 & 1889 & 1898 \\
\hline На 100 мальчиков рождалось девочек & 97,3 & 102,0 & 101,0 & 97,0 \\
\hline На 100 мужчин умирало женщин & 64,4 & 66,9 & 96,4 & 73,9 \\
\hline На 100 родившихся мальчиков приходилось умерших мужчин & 89,4 & 114,4 & 100,5 & 99,7 \\
\hline На 100 родившихся девочек приходилось умерших женщин & 59,1 & 75,0 & 95,9 & 75,9 \\
\hline На 100 родившихся умирало всего & 74,4 & 94,8 & 98,2 & 88,0 \\
\hline
\end{tabular}

Источники: МУ МГА Ф. 12. Оп. 2. Д. 1. Л. 68, Д. 3. Л. 186, Д. 12. Л. 126; Ф. 59. Оп. 2. Д. 1. Л. 50, Д. 3. Л. 198, Д. 16. Л. 348.

\section{ЛИТЕРАТУРА}

1. Ивонин А.Р. Западносибирский город в последней четверти XVIII - 60-х гг. XIX в. (Опыт историко-демографического исследования). Барнаул : Изд-во АГУ, 2000. 337 с.

2. Скубневский В.А., Гончаров Ю.М. Города Западной Сибири во второй половине ХІХ - начале ХХ в. Ч. I: Население. Экономика. Барнаул : Изд-во АГУ, 2003. 360 с. 
3. Гончаров Ю.М. Брачность, рождаемость, смертность в городах Западной Сибири во второй половине ХІХ - начале ХХ в. // Население, управление, экономика, культурная жизнь Сибири XVII - начала ХХ в. Барнаул : Изд-во АГУ, 2003. С. 3-27.

4. Сарафанов Д.Е. Материалы церковно-приходского учета населения как источник для изучения численности и демографического развития населения Барнаула : автореф. дис. ... канд. ист. наук. Барнаул, 2006. 27 с.

5. Винник М.В. Метрические книги как источник для изучения социально-профессиональной структуры населения города Барнаула в последней трети XIX в. // Проблемы народонаселения в зеркале истории. М. : МАКС Пресс, 2010. С. 80-87.

6. Владимиров В.Н., Плодунова В.В., Силина И.Г. Метрические книги как источник по истории народонаселения Алтайского края // Компьютер и историческая демография. Барнаул : Изд-во АГУ, 2000. С. 137-165.

7. Зверев В.А. Семейный демографический календарь: годовой цикл свадеб, рождений и смертей в селениях Сибири (вторая половина XIX - начало XX в.) // Семья в ракурсе социального знания. Барнаул : НП «Азбука», 2001. С. 127-145.

8. Миронов Б.Н. Исповедный и метрический учет в имперской России // Материалы церковно-приходского учета населения как историкодемографический источник. Барнаул : Изд-во АГУ, 2007. С. 32-47.

9. Кискидосова Т.А. Повседневная жизнь горожан Енисейской губернии во второй половине XIX - начале XX века. Абакан : Бригантина; Журналист, 2012. 312 с.

10. Палли Х. Методика использования метрик в историко-демографических исследованиях // История СССР. 1982. № 1. С. $87-93$.

11. Миронов Б.Н. Социальная история России периода империи (XVIII - начала XX вв.): Генезис личности, демократической семьи, гражданского общества и правового государства. СПб. : Дмитрий Буланин, 2003. Т. I. 583 с.

12. Зверев В.А. Воспроизводство сибирского населения на начальном этапе демографического перехода в России // «Сибирь - мой край ...»: проблемы региональной истории и исторического образования. Новосибирск : НГПУ, 1999. С. 130-153.

13. Сарафанов Д.Е. Смертность населения в Барнауле в XIX веке. URL: http: //www. Demoscope.ru/weekly/2007/0301/analit03.php

14. Российский государственный исторический архив.

15. Минусинский городской архив.

16. Сибирь. 1881.

17. Сибирская газета. 1882.

18. Енисейский справочный листок. 1893.

19. Енисей. 1896.

Статья представлена научной редакцией «История» 7 августа 2019 г.

Marriage, Birth and Death Rates of the Orthodox Population in a Siberian Town in the Second Half of the 19th Century (Based on Materials of Church Registers of Orthodox Churches in Minusinsk)

Vestnik Tomskogo gosudarstvennogo universiteta - Tomsk State University Journal, 2020, 450, 120-126.

DOI: 10.17223/15617793/450/15

Tatyana A. Kiskidosova, Khakas Research Institute of Language, Literature and History (Abakan, Russian Federation). E-mail: tak_74@mail.ru

Keywords: Siberia; town; Minusinsk; church registers; marriage rate; birth rate; death rate.

The article is devoted to the study of demographic processes in a Siberian town in the second half of the 19th century on the material of church registers (of two Orthodox churches: the Trinity Church and the Saviour's Cathedral) in Minusinsk. During the period under consideration, Minusinsk was one of the mono-national towns of Siberia with a predominant share of the Russian population. The aim of the article is to analyse the seasonality of births, weddings and deaths, age and sex mortality rates and the general demographic dynamics in the town. Each metric book consists of three thematic sections and contains valuable data on marriage, birth and death. The aggregative processing of primary materials allowed the author to make a primary description of the demographic indicators of the parish. On the basis of data on the population of the parish, the birth, death and marriage rates have been calculated. The greatest number of Minusinsk citizens' marriages falls on winter (January-February), summer (July) and autumn (OctoberNovember) periods. Agrarian cycles also played a significant role in the seasonality of marriages. After harvesting and the end of agricultural work, the period of weddings started in autumn. In December, there were much fewer marriages due to the fasting and Christmas, but their number increased sharply in January and February. The seasonality of conceiving and birth is of interest. The highest number of births in June-July and December shows that children, born in these months, were conceived in SeptemberOctober and in March. The article also analyses the distribution of causes of death in Minusinsk. The distribution of mortality by age groups shows the highest mortality rate during the period of infancy (one year old and younger). The highest number of deaths was in spring (May), summer (June-August) and autumn (October). The article has five tables that summarise the research. Thus, the aggregated analysis of the church registers makes it possible to study many questions of the demographic development of a Siberian town in the epoch of modernisation. Throughout the study period, the town maintained a high mortality rate. The infant mortality rate was especially high due to the poor state of medicine, the unsanitary situation, frequent epidemics and the low cultural level of the population. Townspeople had a traditional model of demographic behaviour. Weddings followed a seasonal logic. The demographic balance in the town remained positive.

\section{REFERENCES}

1. Ivonin, A.R. (2000) Zapadnosibirskiy gorod v posledney chetverti XVIII - 60-kh gg. XIX v. (Opyt istoriko-demograficheskogo issledovaniya) [A West Siberian City in the Last Quarter of the 18th Century to the 1860s (Experience in Historical and Demographic Research)]. Barnaul: Altai State University.

2. Skubnevskiy, V.A. \& Goncharov, Yu.M. (2003) Goroda Zapadnoy Sibiri vo vtoroy polovine XIX - nachale XX v. [Cities of Western Siberia in the Second Half of the 19th - Early 20th Centuries]. Pt. 1. Barnaul: Altai State University.

3. Goncharov, Yu.M. (2003) Brachnost', rozhdaemost', smertnost' v gorodakh Zapadnoy Sibiri vo vtoroy polovine XIX - nachale XX v. [Marriage, Fertility, Mortality in the Cities of Western Siberia in the Second Half of the 19th - Early 20th Centuries]. In: Goncharov, Yu.M. \& Soboleva, T.N. (eds) Naselenie, upravlenie, ekonomika, kul'turnaya zhizn' Sibiri XVII - nachala XX v. [Population, Management, Economics, Cultural Life of Siberia in the 17th - Early 20th Centuries]. Barnaul: Altai State University. pp. 3-27.

4. Sarafanov, D.E. (2006) Materialy tserkovno-prikhodskogo ucheta naseleniya kak istochnik dlya izucheniya chislennosti i demograficheskogo razvitiya naseleniya Barnaula [Materials of Church Parish Registration of the Population as a Source for Studying the Number and Demographic Development of the Population of Barnaul]. Abstract of History Cand. Diss. Barnaul.

5. Vinnik, M.V. (2010) Metricheskie knigi kak istochnik dlya izucheniya sotsial'no-professional'noy struktury naseleniya goroda Barnaula y posledney treti XIX v. [Metric Books as a Source for Studying the Socio-Professional Structure of the Population of Barnaul in the Last Third of 
the 19th Century]. In: Elizarov, V.V. \& Troitskaya, I.A. (eds) Problemy narodonaseleniya v zerkale istorii [Population Problems in the Mirror of History]. Moscow: MAKS Press. pp. 80-87.

6. Vladimirov, V.N., Plodunova, V.V. \& Silina, I.G. (2000) Metricheskie knigi kak istochnik po istorii narodonaseleniya Altayskogo kraya [Metric Books as a Source on the History of Population of Altai Krai]. In: Vladimirov, V.N. (ed.) Komp'yuter i istoricheskaya demografiya [Computer and Historical Demography]. Barnaul: Altai State University. pp. 137-165.

7. Zverev, V.A. (2001) Semeynyy demograficheskiy kalendar': godovoy tsikl svadeb, rozhdeniy i smertey v seleniyakh Sibiri (vtoraya polovina XIX - nachalo XX v.) [Family Demographic Calendar: The Annual Cycle of Weddings, Births and Deaths in the Villages of Siberia (Second Half of the 19th - Early 20th Centuries)]. In: Goncharov, Yu.N. (ed.) Sem 'ya v rakurse sotsial'nogo znaniya [Family in the Perspective of Social Knowledge]. Barnaul: NP “Azbuka”. pp. 127-145.

8. Mironov, B.N. (2007) Ispovednyy i metricheskiy uchet v imperskoy Rossii [Confessional and Metric Accounting in Imperial Russia]. In: Vladimirov, V.N. (ed.) Materialy tserkovno-prikhodskogo ucheta naseleniya kak istoriko-demograficheskiy istochnik [Materials of Church and Parish Registration of the Population as a Historical and Demographic Source]. Barnaul: Altai State University. pp. 32-47.

9. Kiskidosova, T.A. (2012) Povsednevnaya zhizn' gorozhan Eniseyskoy gubernii vo vtoroy polovine XIX - nachale XX veka [Everyday Life of the Citizens of the Yenisei Province in the Second Half of the 19th - Early 20th Centuries]. Abakan: Brigantina; Zhurnalist.

10. Palli, Kh. (1982) Metodika ispol'zovaniya metrik v istoriko-demograficheskikh issledovaniyakh [Methods of Using Metrics in Historical and Demographic Studies]. Istoriya SSSR. 1. pp. 87-93.

11. Mironov, B.N. (2003) Sotsial'naya istoriya Rossii perioda imperii (XVIII - nachala KhKh vv.): Genezis lichnosti, demokraticheskoy sem 'i, grazhdanskogo obshchestva i pravovogo gosudarstva [The Social History of Russia During the Empire (18th - Early 20th Centuries): The Genesis of the Individual, a Democratic Family, Civil Society and the Rule of Law]. Vol. 1. St. Petersburg: Dmitriy Bulanin.

12. Zverev, V.A. (1999) Vosproizvodstvo sibirskogo naseleniya na nachal'nom etape demograficheskogo perekhoda v Rossii [Reproduction of the Siberian Population at the Initial Stage of the Demographic Transition in Russia]. In: Zverev, V.A. (ed.) "Sibir' - moy kray ...”: problemy regional'noy istorii i istoricheskogo obrazovaniya ["Siberia Is My Land . ..": Problems of Regional History and Historical Education]. Novosibirsk: Novosibirsk State Pedagogical University. pp. 130-153.

13. Sarafanov, D.E. (2007) Smertnost' naseleniya v Barnaule v XIX veke [Mortality in Barnaul in the 19th Century]. [Online] Available from: http: //www. Demoscope.ru/weekly/2007/0301/analit03.php

14. Russian State Historical Archive. (In Russian).

15. Minusinsk City Archive.

16. Sibir'. (1881).

17. Sibirskaya gazeta. (1882).

18. Eniseyskiy spravochnyy listok. (1893).

19. Enisey. (1896). 